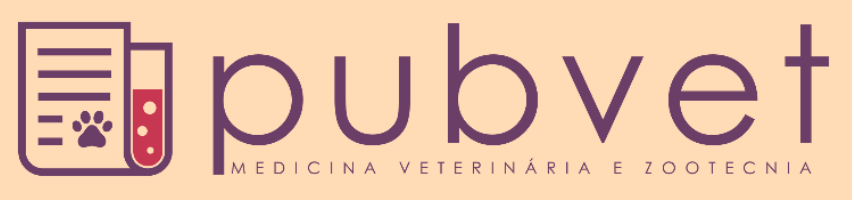

https://doi.org/10.31533/pubvet.v16n01a1021.1-8

\title{
Coleta e avaliação das secreções de vias aéreas posteriores em equinos: Revisão
}

\author{
Matheus Teixeira Borges Pereira ${ }^{1 *} \bullet \mathbb{D}$, Paulo Fernando Rocha de Oliveira ${ }^{10}$, Thailan Silva \\ Martins $^{10}$, Valquiria Tatiele da Silva $\operatorname{Rodrigues}^{10}$, Wendel Denian Silva dos Santos ${ }^{10}$, \\ Dinamérico de Alencar Santos Júnior ${ }^{20}$
}

${ }^{I}$ Discente no curso de Medicina Veterinária - Universidade Federal do Oeste da Bahia (UFOB), Barra - BA, Brasil,

${ }^{2}$ Docente no curso de Medicina Veterinária - UFOB, Barra - BA, Brasil.

*Autor para correspondência, E-mail: matheus.borges@ufob.edu.br

\begin{abstract}
Resumo. As enfermidades respiratórias causam grandes impactos na equinocultura. A determinação do diagnóstico das afecções de caráter inflamatório do sistema respiratório inferior (ou posterior) de equinos depende da associação de histórico e exame clínico em conjunto com os exames complementares, portanto, as intervenções realizadas por profissionais veterinários devem estar sempre amparadas por bons métodos diagnósticos para que seja instituído o tratamento adequado. Como exames complementares, as secreções de vias aéreas inferiores podem ser submetidas a citologia, cultura bacteriana, análise bioquímica, isolamento viral e testes moleculares. Dentre os métodos de coleta destaca-se a utilização das técnicas transtraqueais, entre elas, a lavagem e aspiração transtraqueal percutânea (LPP), a aspiração transtraqueal percutânea (ATP) e a lavagem e aspiração transtraqueal endoscópica (LTE). Além das técnicas transtraqueais, é possível a realização da lavagem broncoalveolar, sendo esta última capaz de colher amostras das vias respiratórias menores e mais distais. O presente estudo visou reunir as principais informações sobre as técnicas de coleta e avaliação das secreções das vias aéreas inferiores em equinos, podendo servir como material auxiliar ao diagnóstico por parte de profissionais veterinários.
\end{abstract}

Palavras-chave: Citologia, equinos, lavados transtraqueais, lavado broncoalveolar

\section{Collection and assessment of posterior airway secretions in horses: Review}

Abstract. Respiratory diseases have great impacts on equine health. Determining the diagnosis of inflammatory conditions of the lower (or posterior) respiratory system in horses depends on the association of history and clinical examination together with complementary exams, therefore, interventions performed by veterinary professionals must always be supported by good diagnostic methods so that the proper treatment is instituted. As complementary exams, the secretions of the lower airways can be submitted to cytology, bacterial culture, biochemical analysis, viral isolation and molecular tests. Among the collection methods, the use of transtracheal techniques stands out, including percutaneous transtracheal aspiration and lavage (LPP), percutaneous transtracheal aspiration (PTA) and endoscopic transtracheal aspiration (LTE). In addition to transtracheal techniques, bronchoalveolar lavage is possible, the latter being able to collect samples from the smaller and more distal airways. The present study aimed to gather the main information on the techniques of collection and evaluation of secretions from the lower airways in horses, which can serve as auxiliary material for diagnosis by veterinary professionals.

Keywords: Cytology, horses, transtracheal lavage, bronchoalveolar lavage 


\section{Introdução}

$\mathrm{Na}$ equideocultura as doenças do sistema respiratório ocupam o segundo lugar entre as enfermidades limitantes, perdendo somente para as afecções musculoesqueléticas, acarretando grandes prejuízos (Dornbusch et al., 2008).

A atividade biológica dos equinos exige adequado funcionamento do sistema respiratório, sendo esses animais capazes de sincronizar os movimentos respiratórios com as fases do galope, de modo a evitar gastos energéticos, fenômeno descrito como "pistão visceral" e utilizado pela espécie para alcançar um ótimo desempenho (Art et al., 1990).

Alterações climáticas, condições de trabalho e manejo inadequado são os principais fatores capazes de acarretar doenças respiratórias e reduzir a performance do animal (Finger et al., 2013), sendo os animais residentes em grandes centros mais expostos a fatores de risco por estarem sujeitos a taxas potencialmente altas de poluição do ar e por permanecerem estabulados por grandes períodos (Lessa et al., 2011).

O diagnóstico presuntivo de inflamações das vias aéreas inferiores em equinos depende da associação de histórico, exame clínico e exames complementares (Di-Filippo et al., 2020), portanto, as intervenções realizadas por veterinários devem estar sempre amparadas pela boa realização das técnicas.

A colheita das secreções é comumente realizada por lavagem traqueal ou lavagem bronco alveolar (Lessa et al., 2005), sendo a segunda técnica capaz de colher amostras das vias respiratórias mais distais (Dzyekanski et al., 2013) necessárias para que seja instituído o tratamento adequado (Roy \& Lavoie, 2003). Como exames complementares, as secreções de vias aéreas inferiores podem ser submetidas a citologia, análise microbiológica, sorologia e outros.

O presente estudo visou reunir informações sobre técnicas de coleta e avaliação das secreções das vias aéreas posteriores em equinos, podendo servir como material auxiliar para a boa realização de diagnósticos por parte de profissionais veterinários.

\section{Revisão de literatura}

Dentre os métodos de coleta destaca-se a utilização das técnicas trans traqueais, pelo fato de permitirem o acesso direto às vias aéreas inferiores, possibilitando a coleta de fluidos do sistema respiratório posterior sem a necessidade de transposição pela porção anterior deste sistema, evitando assim, contaminações que poderiam ocorrer durante a passagem dos materiais de coleta (Hewson \& Viel, 2002; Hodgson \& Hodgson, 2003). As principais técnicas trans traqueais são a lavagem e aspiração trans traqueal percutânea (LPP), a aspiração trans traqueal percutânea (ATP) e a lavagem e aspiração trans traqueal endoscópica (LTE).

\section{Lavagem traqueal}

A produção excessiva de secreções na porção posterior do trato respiratório juntamente com uma debilitação das células ciliadas, responsáveis pela expulsão do excesso de fluido, promove um acúmulo de secreções nas vias aéreas inferiores, principalmente no lúmen traqueal (Roy \& Lavoie, 2003).

Mediante lavagem traqueal, é possível coletar amostras de secreções das grandes vias do trato respiratório (traqueia e brônquios). O método de coleta por lavagem traqueal pode ser feito por punção percutânea ou guiado por endoscópio, sendo ambas as técnicas de fácil execução a campo (Michelotto Júnior et al., 2007).

\section{Lavagem traqueal por punção percutânea}

Para a realização da LPP é preciso que o médico veterinário faça sedação prévia, além de tricotomia e antissepsia seguidas de anestesia local. É um procedimento invasivo em que deverá ser puncionado uma agulha com cateter entre dois anéis traqueais ao nível do terço medial cervical (Figura 1). Em seguida, o cateter será conduzido ao terço distal da traqueia, para então infundir cerca de 20 a $30 \mathrm{ml}$ de solução fisiológica tépida (aquecida a $37^{\circ} \mathrm{C}$ ). Assim que infundida, a solução poderá ser aspirada até que a seringa apresente resistência à aspiração. Caso seja necessário, o realizador poderá repetir a 
administração da solução fisiológica, mas não deverá exceder um total de $100 \mathrm{ml}$ (Schaer \& Orsini, 2007). A principal vantagem da LPP está associada à menor possibilidade de contaminação da amostra, haja vista que a cavidade nasal e trato respiratório anterior não são trajetos na realização dessa técnica (Dzyekanski et al., 2013). Quanto às desvantagens, a técnica é considerada invasiva, com possíveis complicações como abscedação do local incisado, laceração de traqueia, hemorragia, pneumomediastino e inflamação das cartilagens do trato respiratório, além disso, pode ocorrer também a quebra do cateter na traqueia (Roy \& Lavoie, 2003).

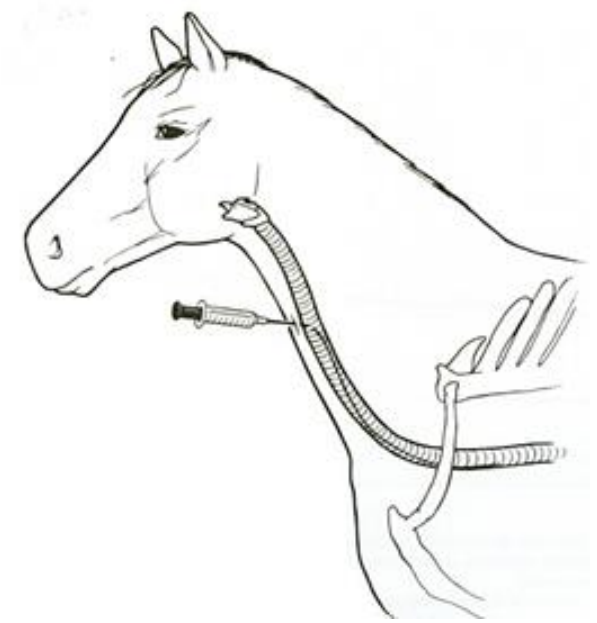

Figura 1. Coleta por punção percutânea das secreções das vias aéreas inferiores. Fonte: Speirs (1999).

\section{Lavagem traqueal via canal de trabalho com endoscópio}

Diferentemente da LPP, a colheita de amostras por LTE, é caracterizada como uma técnica não cruenta que apresenta pouco ou nenhum risco de complicações (Schumacher \& Holl, 2011). Ademais, a utilização da técnica endoscópica permite avaliar as estruturas do sistema respiratório no momento da coleta, fornecendo informações complementares para a interpretação citológica (Hodgson \& Hodgson, 2003).

A LTE descrita por Dzyekanski et al. (2013) utiliza um cateter guiado por endoscópio até a estrutura denominada crista da carina. Em seguida, $30 \mathrm{ml}$ de soro fisiológico, aquecido à temperatura de $37^{\circ} \mathrm{C}$, é administrado. Assim que infundido, a solução é aspirada e acondicionada em um tubo estéril. Já Taylor et al. (2010) recomendam administração de $10 \mathrm{a} 15 \mathrm{ml}$ de solução fisiológica tépida (aquecida a $37^{\circ} \mathrm{C}$ ).

\section{Lavagem bronco alveolar (LBA)}

A LBA é considerada um método sensível para diagnóstico de afecções das vias aéreas posteriores e permite a avaliação do fluido alveolar quanto sua composição, analisando principalmente os níveis celulares e proteicos na secreção. Considerada segura e não invasiva, a técnica pode ser feita com o auxílio de um broncoscópio ou por tubo flexível nasotraqueal guiado, cautelosamente, às cegas. São técnicas parecidas, o que difere os dois métodos é a capacidade do endoscópio em permitir a inspeção do trajeto e a seleção da região alvo do pulmão que fornecerá a amostra (Lessa et al., 2005). Sua utilização objetiva a coleta de fluidos e células presentes nas porções mais distais do trato respiratório inferior, como bronquíolos e alvéolos (Roy \& Lavoie, 2003) (igura 2).

Em experimento, Vitale et al. (2021) realizaram a lavagem bronco alveolar por tubo naso traqueal sem o auxílio do broncoscópio. Inicialmente, um tubo, com três metros de comprimento, dez milímetros de diâmetro e, com um cuff na sua extremidade distal, foi guiado através da cavidade nasal até a bifurcação da traqueia. Em seguida, um anestésico local (lidocaína 2\%) foi diluído a 0,66\% com solução salina a 9\% e assim administrado. Para Hewson \& Viel (2002), 0,4\% de lidocaína em soro fisiológico costuma ser eficaz quando administrado de $60 \mathrm{a} 120 \mathrm{ml}$ próximo à região da crista da carina. Assim que houve a insensibilização da região, o tubo foi guiado até os brônquios segmentares e o cuff foi inflado. Posteriormente, $300 \mathrm{ml}$ de soro fisiológico tépido foi infundido, seguido de aspiração lenta (Vitale et 
al., 2021). Deve-se ressaltar ainda a importância da sedação prévia, bem como a contenção adicional na garantia de uma maior segurança (Van Erck, 2009).

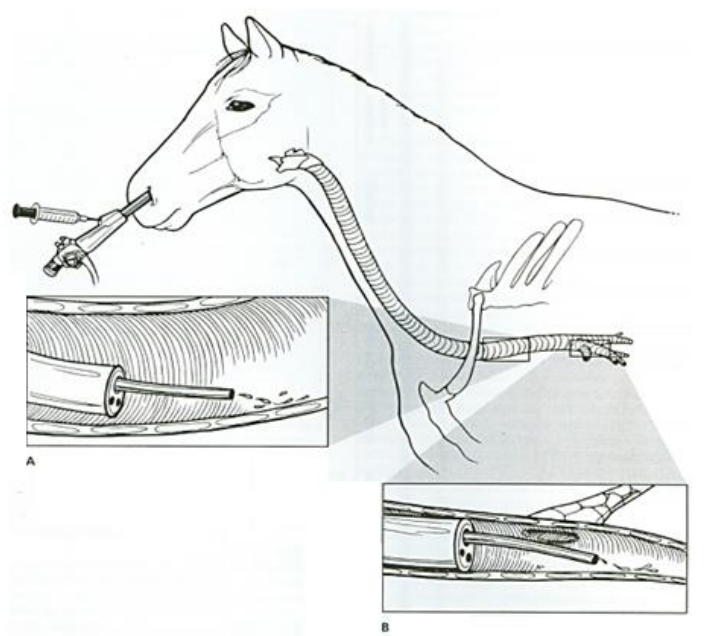

Figura 2. Diferença entre a coleta das secreções das vias aéreas inferiores por lavagem traqueal e lavagem broncoalveolar. A. Aspiração ou lavagem transtraqueal endoscópica. B. Lavagem broncoalveolar. Fonte: Speirs (1999).

Na LBA, recomenda-se a utilização de cateteres flexíveis com 8 milímetros de diâmetro externo. Sem auxílio do broncoscópio, o realizador deverá se atentar as respostas de tosse manifestada pelo animal assim que o cateter atingir a bifurcação traqueal. Assim que manifestados os sinais de hipersensibilidade, o idealizador compreenderá a região alcançada pelo cateter, podendo então, administrar o anestésico tópico a fim de proporcionar conforto ao animal (Hewson \& Viel, 2002). Caso julgue necessário, o realizador da LBA pode ainda fazer uso prévio de bronco dilatadores, com o propósito de reduzir a hiper-reatividade e facilitar a condução do cateter (Lessa et al., 2005).

Os cateteres usados na LBA são específicos para essa técnica. No mercado é possível encontrar cateteres com cuff (BIVONA ${ }^{\circledR}$, Figura 3 ) ou cateteres sem cuff $\left(\right.$ FOGARTY $\left.^{\circledR}\right)$, sendo o primeiro o mais utilizado (McGorum \& Dixon, 1994).

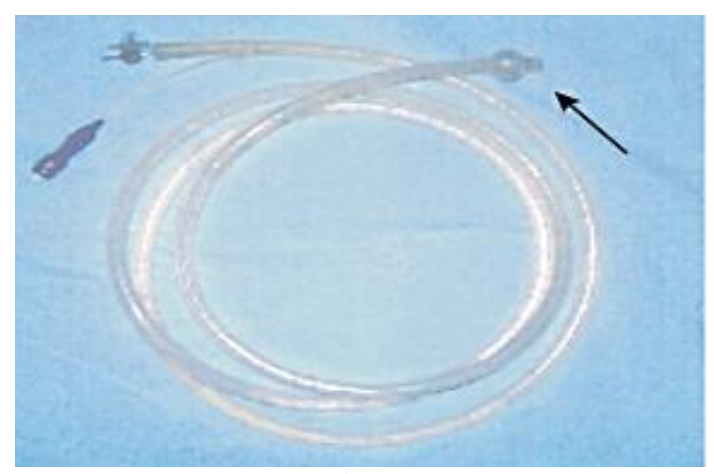

Figura 3. Cateter com cuff $\left(\mathrm{BIVONA}^{\circledR}\right)$ para a coleta de secreções das vias aéreas inferiores de equinos. Fonte: Lessa et al. (2005).

\section{Análise citológica}

O exame citológico é um exame complementar frequentemente utilizado na prática equina para avaliar a saúde do trato respiratório inferior (Finger et al., 2013). Segundo Barrandeguy \& Carossino (2018), os resultados do exame, são bastante úteis para a abordagem de enfermidades nesse trato respiratório. Isso porque a compreensão das características normais das células é essencial para a identificação de processos patológicos (Cian et al., 2015).

Após a coleta, a amostra pode ser armazenada em tubo com ácido etilenodiamino tetra-acético (EDTA) ou em tubo sem anticoagulante. O EDTA retarda a coagulação, preserva a estrutura morfológica das células e retarda o crescimento de bactérias, sendo indicado para exames como a citologia. Contudo, 
as bactérias anaeróbias são sensíveis ao EDTA, logo as amostras destinadas à cultura bacteriana devem ser armazenadas em tubos sem anticoagulante (Hoffman, 2008).

Ademais, antes de encaminhar a amostra para o exame específico (citologia, cultura bacteriana, análise bioquímica, isolamento viral e teste molecular), as características macroscópicas deverão ser avaliadas. Amostras sem interferência de qualquer tipo de doença se apresentam inodoras, claras ou levemente turvas, além de aspecto espumoso devido a presença de surfactante produzido pelas células pneumócitos tipo II (Hoffman, 2008).

Durante a realização do exame citológico, é de extrema importância a contagem total das células presentes para a estimativa de celularidade da amostra e interpretação dos resultados obtidos na contagem diferencial, esta contagem pode ser influenciada pela presença de muco, processamento da amostra, método de contagem e quantidade de solução fisiológica utilizada (Richard et al., 2010). Todavia, como demonstrado por Viscardi et al. (2015), é inadequado comparar os resultados obtidos do lavado bronco alveolar com a infusão de $250 \mathrm{ml}$ de solução salina com os valores de referência.

Na citologia do lavado bronco alveolar, as células mais predominantes são macrófagos alveolares, linfócitos, número reduzido de células epiteliais ciliadas, não ciliadas, eosinófilos e neutrófilos compreende menos que 5\% das células nucleadas (Hoffman, 2008). Em relação a citologia do lavado traqueal, não há referência universalmente aceita para a contagem diferencial de células, geralmente são observadas células ciliadas e células epiteliais colunares respiratórias não ciliadas, pode ser observado também número moderado de macrófagos e números baixos de linfócitos e neutrófilos (Cian et al., 2015).

Na hemorragia pulmonar induzida por exercício é comum identificar hemossiderófagos em amostras de secreções aéreas posteriores de equinos submetidas ao exame citológico (Lessa et al., 2007). Já o aumento do número de eosinófilos pode ser sugestivo de hipersensibilidade e pode ser observada também em bronquite alérgicas e infecções parasitária (Cian et al., 2015), além disso pode ser observado o aumento dessas células em equinos acometido por doença inflamatória das vias respiratórias (Couëtil et al., 2007). Já os neutrófilos que são células raras na citologia do lavado traqueal e lavado bronco alveolar, quando estão em número aumentado, podem ser indicativos de inflamação neutrofílica, associada à alguma causa séptica ou não séptica, como obstrução recorrente das vias aéreas e doença inflamatória das vias aéreas (Cian et al., 2015). Segundo Couëtil et al. (2016), citologia do lavado bronco alveolar apresentam resultados mais confiáveis quando comparado a citologia de amostras do lavado traqueal, devido a amostra coletada por LBA ser proveniente das porções mais distais do trato respiratório.

\section{Análise microbiológica}

Cumming \& Semple (1980) afirmam que as doenças do sistema respiratório devem ser tratadas com antibióticos selecionados a partir de cultura bacteriana e resultados de sensibilidade do aspirado traqueobrônquico. Para a realização de cultura bacteriana, as amostras devem ser colhidas, preferencialmente, por via transcutânea sob rigorosas técnicas assépticas ou por canal de biópsia de um endoscópio com cateter estéril para evitar possível contaminação ao passar pelas vias aéreas superiores (Darien et al., 1990). As enfermidades respiratórias, juntamente com doenças reprodutivas, gastrointestinais e cutâneas são as principais doenças de cavalos tratadas com antimicrobianos. A utilização destes medicamentos se faz necessária para reverter quadros patológicos de caráter bacteriano e assim garantir o bem-estar animal. Contudo, o uso empírico de antimicrobianos contribui para a resistência bacteriana, o que prejudica a eficácia do tratamento (Souza et al., 2020).

Dentre as doenças respiratórias mais comuns em cavalos adultos, tem-se a pneumonia bacteriana por aspiração de microrganismos que habitam a flora da cavidade nasal. Transporte dos animais por longos períodos, exercícios de alta intensidade e confinamento com fornecimento do volumoso em suportes suspensos são fatores que aumentam a possibilidade de proliferação de microrganismos em vias aéreas inferiores, visto que os cavalos precisam manter a cabeça baixa por alguns períodos do dia para assegurar a atividade mucociliar (Racklyeft \& Love, 1990). O Streptococcus beta-hemolíticos ( $S$. equi) é o patógeno mais encontrado em cultura bacteriana de cavalos com broncopneumonia (Reuss \& Giguère, 2015) (Tabela 1). 
Reuss \& Giguère (2015) destacam a importância da interpretação dos resultados da cultura bacteriana e que os achados devem sempre ser associados aos exames clínicos e à citologia. Se há pequena quantidade de bactérias cultivadas na ausência de evidência de sepse no resultado citológico, é pouco provável que sejam a causa primária da afecção. Em situações mais graves, ainda é mais importante definir o tratamento com base na cultura bacteriana e antibiograma. No entanto, à medida que se aguarda os resultados, a antibioticoterapia de amplo espectro inicial é necessária. $\mathrm{O}$ tratamento usualmente utilizado nesses casos é a associação da gentamicina e penicilina, para a cobertura das gramnegativas e gram-positivas, respectivamente (Reuss \& Giguère, 2015).

Tabela 1. Principais bactérias isoladas de animais com broncopneumonia.

\begin{tabular}{cccc}
\hline $\begin{array}{c}\text { Bactérias Gram-negativas } \\
\text { não entéricas }\end{array}$ & $\begin{array}{c}\text { Bactérias Gram-negativas } \\
\text { entéricas }\end{array}$ & Bactérias Gram-positivas aeróbias & \multirow{2}{*}{ Bactérias anaeróbias } \\
\hline Pasteurella $\mathrm{spp}$ & Klebsiella $\mathrm{spp}$ & Streptococcus beta-hemolíticos & Bacteroides $\mathrm{spp}$ \\
Actinobacillus $\mathrm{spp}$ & Escherichia coli & Staphylococcus spp & Clostridium $\mathrm{spp}$ \\
Bordetella $\mathrm{spp}$ & Enterobacter $\mathrm{spp}$ & Rhodococcus equi & Peptostreptococcus spp \\
Pseudomonas $\mathrm{spp}$ & Salmonella enterica & Streptococcus pneumoniae & Fusobacterium $\mathrm{spp}$ \\
& & & Prevotella $\mathrm{spp}$ \\
\hline
\end{tabular}

Fonte: Adaptado Reuss \& Giguère (2015).

\section{Outros exames complementares}

As infecções de origem viral que acometem o sistema respiratório dos equinos, provocam sérios danos, tais como morte celular, erosão do epitélio e distúrbios do mecanismo clearance mucociliar, comprometendo as funções desse trato respiratório contra infecções bacterianas secundárias (Wilkins, $\underline{2003}$ ). Dentre os agentes virais que provocam infecções respiratórias de maior importância, destacamse o vírus influenza, herpes vírus equino (HVE), o vírus da artrite equina (AVE) e o adenovírus equino (Nolen-Walston et al., 2013). A confirmação de agentes virais acometendo o trato respiratório pode-se dar por meio de isolamento ou detecção do vírus ou testes sorológicos, tais como hemaglutinação e soroneutralização (Wilkins, 2003).

O teste Enzyme Linked Immuno-Sorbent Assay (ELISA) é uma técnica com base na interação específica do anticorpo com antígeno (Mota \& Duarte, 2010) sendo de grande valia para a avaliação da amostra das secreções de vias aéreas coletadas por LBA (Carvalho Filho et al., 2019).

Concentrações elevadas da proteína C reativa, da proteína haptoglobina (HP) e da proteína amilóide A sérica (AAS) no soro é indicativo de inflamação, sendo a AAS a proteína de maior pronunciamento a uma reação de fase aguda (Carvalho Filho et. al., 2019). Estudos recentes estão buscando descrever a detecção da AAS no fluido de lavagem broncoalveolar mediante teste ELISA. Já a HP em equinos pode ser usada como marcador de hemólise durante o exercício (Di-Filippo et al., 2020).

\section{Considerações finais}

O conhecimento sobre as técnicas de coleta e avaliação de amostras do sistema respiratório são indispensáveis ao diagnóstico preciso das afecções do sistema respiratório dos equídeos, portanto, espera-se com esse trabalho poder contribuir com formação de alunos e médicos veterinários atuantes na medicina equina.

O método de coleta deve ser escolhido com base no teste que se pretende realizar, nos materiais disponíveis e na habilidade do idealizador. Independentemente da técnica de colheita, a mesma deve ser realizada sob adequada sedação e contenção do paciente, a fim de garantir maior segurança ao realizador e ao animal.

As amostras colhidas podem ser submetidas a citologia, cultura bacteriana, entre outros, e cabe ao médico veterinário solicitar os testes que julgar indispensáveis, de acordo com suas condições de trabalho. A confiabilidade dos resultados na avaliação das secreções está intrinsecamente relacionada com a correta execução das técnicas de colheita e armazenamento das amostras.

Adicionalmente, os resultados obtidos mediante avaliação das secreções de vias aéreas inferiores de equinos precisam ser associados aos achados clínicos, histórico e resultados de outros exames complementares, a fim de determinar um diagnóstico preciso. 


\section{Referências bibliográficas}

Art, T., Desmecht, D., Amory, H., \& Lekeux, P. (1990). Synchronization of locomotion and respiration in trotting ponies. Journal of Veterinary Medicine, 37(1-10), 95-103. https://doi.org/10.1111/j.14390442.1990.tb00880.x.

Barrandeguy, M. E., \& Carossino, M. (2018). Infectious diseases in donkeys and mules: an overview and update. Journal of Equine Veterinary Science, 65, 98-105. https://doi.org/10.1016/j.jevs.2018.02.026.

Carvalho Filho, W. P., Fonseca, L. A., Girardi, F. M., Bento, L. D., Souto, P. C., \& Orozco, A. M. O. (2019). Serum amyloid A and muscle activity biomarkers in horses submitted to equestrian show jumping. Brazilian Journal of Veterinary Research and Animal Science, 668-671.

Cian, F., Monti, P., \& Durham, A. (2015). Cytology of the lower respiratory tract in horses: An updated review. Equine Veterinary Education, 27(10), 544-553. https://doi.org/10.1111/eve.12376.

Couëtil, L L, Cardwell, J. M., Gerber, V., Lavoie, J., Léguillette, R., \& Richard, E. A. (2016). Inflammatory airway disease of horses - revised consensus statement. Journal of Veterinary Internal Medicine, 30(2), 503-515. https://doi.org/10.1111/jvim.13824.

Couëtil, Laurent L, Hoffman, A. M., Hodgson, J., Buechner-Maxwell, V., Viel, L., Wood, J. L. N., \& Lavoie, J. (2007). Inflammatory airway disease of horses. Journal of Veterinary Internal Medicine, 21(2), 356-361. https://doi.org/10.1111/j.1939-1676.2007.tb02975.x.

Cumming, G., \& Semple, S. J. (1980). Disorders of the respiratory system.

Darien, B. J., Brown, C. M., Walker, R. D., Williams, M. A., \& Derksen, F. J. (1990). A tracheoscopic technique for obtaining uncontaminated lower airway secretions for bacterial culture in the horse. Equine Veterinary Journal, 22(3), 170-173. https://doi.org/10.1111/j.2042-3306.1990.tb04239.x.

Di-Filippo, P. A., Ribeiro, L. M. F., Meireles, M. A. D., Lannes, S. T., Mello, L., Gobbi, F. P., Toledo, L. F. A., \& Lessa, D. A. B. (2020). ELISA of amyloid A in paired bronchoalveolar lavage fluid and serum samples of healthy horses. Pesquisa Veterinária Brasileira, 40, 381-384. https://doi.org//10.1590/1678-5150-PVB-6311.

Dornbusch, P. T., Leite, S. C., Círio, S. M., Pimpão, C. T., Lunelli, D., Michellotto Junior, P. V, \& Leite, L. C. (2008). Análise dos ruídos respiratórios de cavalos atletas no diagnóstico da hemiplegia de laringe. Archives of Veterinary Science, 13(3), 184-190. https://doi.org/10.5380/avs.v13i3.13134.

Dzyekanski, B., de Almeida, S. R. P., Rocha, D. C. C., Lopes, A. C. A. M., Pimpão, C. T., Junior, J. A. V., \& Júnior, P. V. M. (2013). Results of the combined use of tracheal and bronchoalveolar lavages for the diagnosis of horses airway diseases. Revista Acadêmica Ciência Animal, 11(4), 359-365. https://doi.org/10.7213/academico.011.004.AO02.

Finger, M. A., Leite, S. C., Dornbusch, L. P. T. C., Deconto, I., Barros Filho, I. R., \& Dornbusch, P. T. (2013). Avaliação clínica e citológica de cavalos de tração, acometidos por doenças respiratórias das vias aéreas inferiores no Paraná. Archives of Veterinary Science, 18(2), 20-26. https://doi.org/10.5380/avs.v18i2.28469

Hewson, J., \& Viel, L. (2002). Sampling, microbiology and cytology of the respiratory tract. In P. Lekeux (Ed.), Equine respiratory diseases (pp. B0308-B0602). International Veterinary Information Service Ithaca.

Hodgson, J. L., \& Hodgson, D. R. (2003). Tracheal aspirates: indications, technique and interpretation. In N. E. Robinson (Ed.), Current Therapy in Equine Medicine (pp. 401-406).

Hoffman, A. M. (2008). Bronchoalveolar lavage: sampling technique and guidelines for cytologic preparation and interpretation. Veterinary Clinics of North America: Equine Practice, 24(2), 423435. https://doi.org/10.1016/j.cveq.2008.04.003.

Lessa, D. A. B., Jorge, M. L. L. A., Viana, E. B., Alencar, N. X., \& Fernandes, W. R. (2011). Análise do líquido broncoalveolar de equinos portadores de doença inflamatória das vias aéreas. Brazilian Journal of Veterinary Research and Animal Science, 48(2), 123-130. https://doi.org/10.11606/s1413-95962011000200004.

Lessa, D. A. B., Machado, C. H., Duarte, C. S., Wachholz, L., Lima, J. R. P. A., \& Fernandes, W. R. (2005). Enfermidades do trato respiratório posterior em eqüinos de equitação no Rio de Janeiro: prevalência e aspectos clínico-laboratoriais. Revista Brasileira de Ciência Veterinária, 12(1-3), 77 - 
83. https://doi.org/10.4322/rbcv.2014.308.

Lessa, D. A. B., Mori, E., Viana, E. B., dos Santos, O. J., Moreira, J. F. E., \& Fernandes, W. R. (2007). Lavado broncoalveolar em eqüinos: revisão de literatura parte 2: achados citológicos. Arquivos de Ciências Veterinárias e Zoologia Da Unipar, 10(1), 31-38.

McGorum, B. C., \& Dixon, P. M. (1994). The analysis and interpretation of equine bronchoalveolar lavage fluid (BALF) cytology. Equine Veterinary Education, 6(4), 203-209. https://doi.org/10.1111/j.2042-3292.1994.tb01136.x.

Michelotto Júnior, P. V, Biava, J. S., Gonçalves, R. C., Cassou, F., Bonfá, A. F., \& Machado, C. D. (2007). Aspirado traqueal de cavalos clinicamente sadios da raça Quarto de milha após prova de três tambores. Archives of Veterinary Science, 12(2). https://doi.org/10.5380/avs.v12i2.9899.

Mota, T. P., \& Duarte, K. M. R. (2010). ELISA na detecção de aflatoxinas em alimentos. PUBVET, 4(42), Art. 989.

Nolen-Walston, R. D., Harris, M., Agnew, M. E., Martin, B. B., Reef, V. B., Boston, R. C., \& Davidson, E. J. (2013). Clinical and diagnostic features of inflammatory airway disease subtypes in horses examined because of poor performance: 98 cases (2004-2010). Journal of the American Veterinary Medical Association, 242(8), 1138-1145. https://doi.org/10.2460/javma.242.8.1138.

Racklyeft, D. J., \& Love, D. N. (1990). Influence of head posture on the respiratory tract of healthy horses. Australian Veterinary Journal, 67(11), 402-405. https://doi.org/10.1111/j.17510813.1990.tb03028.x.

Reuss, S. M., \& Giguère, S. (2015). Update on bacterial pneumonia and pleuropneumonia in the adult horse. Veterinary Clinics: Equine Practice, 31(1), 105-120. https://doi.org/10.1016/j.cveq.2014.11.002.

Richard, E. A., Fortier, G. D., Lekeux, P. M., \& Van Erck, E. (2010). Laboratory findings in respiratory fluids of the poorly-performing horse. The Veterinary Journal, 185(2), 115-122. https://doi.org/10.1016/j.tvj1.2009.05.003.

Roy, M.-F., \& Lavoie, J.-P. (2003). Tools for the diagnosis of equine respiratory disorders. Veterinary Clinics: Equine Practice, 19(1), 1-17. https://doi.org/10.1016/S0749-0739(02)00063-9.

Schaer, B. D., \& Orsini, J. A. (2007). Respiratory system. Diagnostic and therapeutic procedures. In J. A. Orsini \& T. Divers (Eds.), Equine emergencies: treatment and procedures (pp. 436-439). Sauders Elsevier.

Schumacher, J., \& Holl, H. D. (2011). Collection of lower airway secretion. In J. Schumacher \& H. D. Holl (Eds.), A manual of equine diagnostic procedures (pp. 1-6). Jackson, WY: Teton New Media.

Souza, K. L. S., Fuzatti, J. V. S., Camargo, R. C., Pinto, M. S., Silva, T. K., \& Frias, D. F. R. (2020). Prevalência de bactérias multirresistentes na cavidade nasal de equinos assintomáticos para doenças respiratórias. Revista Univap, 26(52), 107-123. https://doi.org/10.18066/revistaunivap.v26i52.2515.

Speirs, V. C. (1999). Exame Clínico de equinos. Artmed. Porto Alegre, p. 55-58.

Taylor, I. G. R., Brazil, T. J., \& Hillyer, M. H. (2010). Respiratory diseases. In Diagnostic techniques in equine medicine (pp. 217-248). Sauders Elsevier.

Van Erck, E. (2009). Sampling the respiratory tract: techniques and interpretation. Congress on Equine Medicine and Surgery, 45-47.

Viscardi, V., Lopes, A. C. G., Beling, J. C. F., Gioia, G. V., Torres Filhos, R. A., Lessa, D. A. B., \& Alencar, N. X. (2015). Effects of single and duplicate infusions of $250 \mathrm{~mL}$ of saline solution in the cytological evaluation of bronchoalveolar lavage in equines. Brazilian Journal of Veterinary Medicine, 37(1), 33-35.

Vitale, V., Bonelli, F., Briganti, A., \& Sgorbini, M. (2021). Bronchoalveolar lavage fluid cytological findings in healthy Amiata donkeys. Open Veterinary Journal, 11(1), 160-164. https://doi.org/10.4314/ovj.v11i1.23 .

Wilkins, P. A. (2003). Lower airway diseases of the adult horse. Veterinary Clinics: Equine Practice, 19(1), 101-121. https://doi.org/10.1016/S0749-0739(02)00069-X.

Histórico do artigo:

Recebido: 16 de outubro de 2021

Aprovado: 15 de novembro de 2021

Disponível online: 31 de dezembro de 2021
Licenciamento: Este artigo é publicado na modalidade Acesso Aberto sob a licença Creative Commons Atribuição 4.0 (CC-BY 4.0), a qual permite uso irrestrito, distribuição, reprodução em qualquer meio, desde que o autor e a fonte sejam devidamente creditados. 